\title{
Cure Characteristics, Mechanical and Swelling Properties of Marble Sludge Filled EPDM Modified Chloroprene Rubber Blends
}

\author{
Khalil Ahmed $^{1 *}$, Shaikh Sirajuddin Nizami ${ }^{2}$, Nudrat Zahid Raza ${ }^{1}$, Khaula Shirin ${ }^{1}$ \\ ${ }^{1}$ Applied Chemistry Research Centre, Pakistan Council of Scientific and Industrial Research Laboratories Complex, \\ Karachi, Pakistan \\ ${ }^{2}$ Department of Chemistry, University of Karachi, Karachi, Pakistan \\ Email: ${ }^{*}$ khalilmsrc@gmail.com
}

Received December 16, 2011; revised February 1, 2012; accepted April 26, 2012

\begin{abstract}
In the present study, attempts have been made to modify Marble Sludge (MS) filled Ethylene-propylene-diene monomer (EPDM) with Chloroprene rubber (CR). Compounding was carried out on a two-roll mill and vulcanized at $155^{\circ} \mathrm{C}$. The modified blend of MS filed EPDM/CR was characterized on the basis of the effect of blend ratio on cure characteristics, mechanical and swelling properties of blends were investigated. The effect of thermal aging on mechanical and swelling behavior in aromatic, aliphatic and chlorinated solvents of cured MS filled EPDM/CR blend was also examined. The minimum torque and maximum torque of the blend first increased and then slightly decreased after the increasing of CR content in MS filled EPDM/CR blends. Scorch time, cure time, cure rate index, tensile strength, tear strength, hardness increased with increasing CR content in the MS filled EPDM compound, but elongation at break, resilience, abrasion loss, mole \% uptake, swelling index and percentage of soluble fraction decreased, resilience, abrasion loss, mole \% uptake, swelling index and percentage of soluble fraction decreases. Accelerated aging performance of cured composites also influenced by increasing CR content in MS filled EPDM compound.
\end{abstract}

Keywords: Marble Sludge; Cure Characteristics; Mechanical Properties; Swelling Parameters; Aging

\section{Introduction}

A blending of two or more polymers of physical or chemical means is to improve a variety of physical and chemical properties of the constituent polymers. The blending of rubbers plays an important role in enhancing the physical properties of the final vulcanized product. The rubber blends are frequently used in rubber industry to obtain the best combination of compound properties, processablity and cost. Ethylene-propylene-diene monomer (EPDM) is obtained by polymerizing ethylene and propylene with small amount of non conjugated diene, which imparts usually good aging property, good weathering, oxidation and chemical resistance, high mechanical and electrical properties. Usually the blending of EPDM rubber with other rubber have given the compounds with good physical properties [1-12].

On the other side Chloroprene rubber (CR) is one of the earliest synthetic rubbers. It was developed by the $\mathrm{Du}$ Pond in 1931. Vulcanized CR has excellent oil resistance; therefore CR remains an important material in the formulations of rubber blends and composition. The difficulties

${ }^{*}$ Corresponding author. encountered in the processing and vulcanization of some rubber also emphasize the need for blending. Economic reasons can also be given for blending since appreciable price difference exists between different rubbers for example the resistance of $\mathrm{CR}$ to ozone is excellent but its price is high and accordingly blending of CR with cheaper rubber is normally in practice for various applications [13-16].

In recent years several investigations have been reported on the replacement of carbon black with light or white in color natural and mineral fillers such as silica sand [17] clay [18] and calcium carbonate [19] as a result of the high cost of carbon black and pollution problems.

Marble Sludge powder (MS) is very low cost inorganic waste product of marble cutting the industry is passing a menace and hence requires to be utilized for curbing environmental pollution. Attempts have been made to utilized marble waste for various purposes in cement $\&$ the construction industry [20] and asphaltic concrete [21]. However very few attempts have been made to use as a filler in rubber [22].

Therefore, significant research and development attempts are being performed to investigate the possibility 
to use the marble sludge waste with the goal of reducing cost and desired properties. Therefore, the major aim of this investigation was to develop modified MS filled EPDM/CR blend and characterized on the basis of the effect of CR content in EPDM/CR blend. The studies were involved Cure characteristics, mechanical properties and swelling behavior of $\mathrm{CR}$ ratio in MS filled EPDM/CR blends. The mechanical tests include tensile strength, elongation at break tear strength, compression set, hardness, abrasion resistance and rebound resilience. Swelling test was conducted by measuring the mole $\%$ uptake, swelling index and percentage of soluble fraction in three different solvents. The aging behavior of corresponding MS filled EPDM/CR blend was also evaluated at $100^{\circ} \mathrm{C}$ aging temperatures.

\section{Material and Methods}

\subsection{Materials}

Ethylene Propylene Dien Monomer rubber (EPDM as grade Keltan 4703) Mooney viscosity [ $\left(\mathrm{ML}_{1+4}\right.$ at $\left.125^{\circ} \mathrm{C}\right)$ $65]$, ethylene content $48 \%$ ENB 9\% was purchased from local market.

Chloroprene rubber (CR) as Bayprenne based on 2chloro-1,3-butadiene was obtained from Rain bow rubber industry Karachi.

Other materials used for the preparation of the compounds were:

1) Zinc oxide;

2) Magnesium oxide;

3) Stearic acid;

4) Tetramethylthiuram disulphide (TMTD);

5) Mercapto benzo thiozole (MBT);

6) Sulphur.

All materials were commercially obtained from local market. Toluene, n-hexane and carbon tetrachloride was purchased from Merck. Marble waste as the dried marble slurry powder was collected from marble cutting industry washed, dried in oven then ground and passed through desired $10 \mu \mathrm{m}$ sieves.

\subsection{Methods}

\subsubsection{Compounding}

The raw rubber such as EPDM and CR were first masticated on the laboratory open two roll mill (XK 160) for ten minutes. The required amount of $\mathrm{MgO}$ was incorporated with $\mathrm{CR}$ on a two roll mill at first. Zinc oxide, stearic acid and other rubber additives were added sequentially in masticating EPDM rubber. Finally, CR rubber with magnesium oxide was mixed with the EPDM rubber compounds for another ten minutes. The mixing mill was cooled by cold water circulation during the mixing of all rubbers and rubber additives. The compounds were prepared as per formulation given in Table 1 According to ASTM method D 3182.
Table 1. Compound formulation.

\begin{tabular}{cccccccc}
\hline \multirow{2}{*}{ Ingredient } & \multicolumn{7}{c}{ Compound $^{\#}$} \\
\cline { 2 - 8 } & $\mathrm{K}_{1}$ & $\mathrm{~K}_{2}$ & $\mathrm{~K}_{3}$ & $\mathrm{~K}_{4}$ & $\mathrm{~K}_{5}$ & $\mathrm{~K}_{6}$ & $\mathrm{~K}_{7}$ \\
\hline EPDM & 100 & 97.5 & 95 & 90 & 85 & 80 & 75 \\
CR & 0 & 2.5 & 5.0 & 10 & 15 & 20 & 25 \\
MS & 60 & 60 & 60 & 60 & 60 & 60 & 60 \\
ZnO & 5 & 5 & 5 & 5 & 5 & 5 & 5 \\
MgO & 2 & 2 & 2 & 2 & 2 & 2 & 2 \\
St. Acid & 2 & 2 & 2 & 2 & 2 & 2 & 2 \\
TMTD & 0.8 & 0.8 & 0.8 & 0.8 & 0.8 & 0.8 & 0.8 \\
MBT & 0.6 & 0.6 & 0.6 & 0.6 & 0.6 & 0.6 & 0.6 \\
Sulpher & 2 & 2 & 2 & 2 & 2 & 2 & 2 \\
ML (dNm) & 0.6 & 0.76 & 0.87 & 0.95 & 1.06 & 0.99 & 0.98 \\
MH (dNm) & 2.63 & 2.80 & 2.92 & 2.88 & 2.83 & 2.75 & 2.70 \\
$\mathrm{t}_{90}($ mint) & 16.28 & 14.55 & 13.86 & 15.60 & 19.05 & 19.62 & 21.29 \\
$\mathrm{t}_{\mathrm{S} 2}$ (mint) & 2.39 & 2.67 & 2.92 & 4.78 & 9.52 & 10.91 & 13.88 \\
CRI & 7.2 & 8.41 & 9.15 & 9.24 & 10.50 & 11.48 & 11.9 \\
\hline
\end{tabular}

\subsubsection{Curing}

The aromatic characteristics, the minimum torque $\left(\mathrm{M}_{\mathrm{L}}\right)$ maximum torque $\left(\mathrm{M}_{\mathrm{H}}\right)$ delta torque $(\Delta \mathrm{H})$ Cure rate index $(\mathrm{CRI})$, the cure time $\left(\mathrm{t}_{90}\right)$ and scorch time $\left(\mathrm{t}_{\mathrm{S} 2}\right)$ were determined using a Monsanto Moving Die Rheometer (MDR 2000) according to ASTM method D 2084. Samples of about $6 \mathrm{gm}$ of the respective compounds were tested at a vulcanization temperature of $155^{\circ} \mathrm{C}$. The cure rate index is a parameter which indicates the speed of curing reaction was determined from rheometric data. $\mathrm{CRI}$ is calculated using the following relation.

$$
\mathrm{CRI}=\frac{100}{\text { cure time }- \text { scorch time }}
$$

\subsubsection{Vulcanization Process}

Sheet of $2.5 \mathrm{~mm}$ thickness was compressed and molded at $155^{\circ} \mathrm{C} \pm 2{ }^{\circ} \mathrm{C}$ with $10 \mathrm{MPa}$ force using a hot laboratory press at the respective cure time $\left(\mathrm{t}_{90}\right)$ determined with the MDR 2000.

\subsection{Characterization of Blends}

1) Tensile strength and elongation at break

Tensile strength (TS) and percentage of elongation at break (\% EB) were carried out in a tensile testing machine (Instron 4301) according to ASTM D 412 test method using dumb-bell shaped test specimens at a uniform speed $8.33 \mathrm{~mm} \cdot \mathrm{s}^{-1}$, The failure properties were calculated using the following equation.

$$
\mathrm{TS}\left(\mathrm{kgf} / \mathrm{cm}^{2}\right)=\frac{\text { Load failure }}{\text { Area of cross section }}
$$




$$
\% \mathrm{~EB}=\frac{\text { Displace at failure }}{\text { Effective gauge length }} \times 100
$$

\section{2) Tear strength}

The tear strength of un-nicked 90 angle test specimens were carried out as per ASTM D 624 under the same condition of tensile strength testing. The following equation used for calculating the tear strength.

$$
\text { Tear str. }(\mathrm{kgf} / \mathrm{cm})=\frac{\text { Load failure }}{\text { Thickness }}
$$

\section{3) Hardness}

The hardness of the blends measured as per ASTM D 2240 test method. Reported hardness values are the average of reading taken at five different locations on each sample at room temperature.

\section{4) Abrasion loss}

Abrasion test was conducted using an ASTM D5963 test method. The abrasion resistance has been expressed as relative volume loss $\mathrm{mm}$. The test was conducted on an Abrasion chick from Gibitre Italy.

5) Resilience

The resilience of the blends was measured as per ASTM D2832. In this method, a plunger suspended from a given height above the sample was released and the rebound height was determined. The ratio of the rebound height and original height is referred to as the resilience and expressed as a percentage. The test was performed on Rebound check from Gibitre Italy.

6) Thermoxidative aging

The thermoxidative aging characteristics of the vulcanized blends were studied by aging for 96 hours at $100^{\circ} \mathrm{C}$ as per ASTM D573. The properties of accelerated aging were measured after 24 hours of aging test. Tensile strength, elongation at break, tear strength, resilience, abrasion loss and swelling parameters of the blends after aging to estimate aging resistance. Percentage of retention in properties of the specimens is calculated as below.

$$
\% \text { Retention }=\frac{\text { Value after aging }}{\text { Value before aging }} \times 100
$$

\subsection{Swelling Parameters}

Swelling behavior was determined by the change in mass using the following method. For cured rubber blends vulcanized the test pieces of known weight $\left(W_{2}\right)$ were immersed in toluene, $n$-hexane and carbon tetrachloride in diffusion test bottles and kept at room temperature for five days. Samples were removed from the bottles after five days and the wet surfaces were quickly wiped using tissue paper and re-weighted $\left(W_{1}\right)$. The test samples of the blends were further dried in an oven at $60^{\circ} \mathrm{C}$ for 24 hours, cooled in a desiccator and immediately weighed $\left(W_{3}\right)$. The swelling parameters of blends were calculated by the following swelling data.
1) $\mathrm{Mol} \%$ uptake $\left(Q_{t}\right)$

The mol \% uptake of the solvent " $Q_{t}$ " for the MS filled EPDM/CR blends was determined by the following equation.

$$
\mathrm{Q}_{\mathrm{t}} \%=\frac{\left(W_{2}-W_{1}\right) / W_{1}}{W_{m}} \times 100
$$

2) Swelling index (SI)

Swelling index (SI) was calculated by the equation.

$$
\text { SI } \%=\left(W_{1}-W_{2}\right) / W_{2} \times 100
$$

3) Solubility $\%$

Soluble fraction (SF \%) was determined by the following relation.

$$
\mathrm{SF} \%=\left(W_{2}-W_{3}\right) / W_{2} \times 100
$$

where:

$W_{2}=$ Initial Weight/dry weight;

$W_{1}=$ Swollen Weight;

$W_{3}=$ Deswollen Weight;

$W_{m}=$ Molar mass of Solvent.

\section{Result and Discussion}

\subsection{Characterization of Marble Powder}

The MS obtained from the scheme: The chemical composition of MS was determined using WDX-ray fluorescence spectrometer (model S4 pioneer Bruker AXS, Germany) is shown in the Table 2. It is evident from the chemical analysis that MS contain the calcium and magnesium compounds in large amount. Silica, aluminum oxide and iron oxide also present but in small amount. The values obtained for relative metal composition of marble powder from Atomic Absorption Spectroscopy (AAS) study are in close approximation with those obtained from WDX-ray florescence spectrometer study.

Table 2. Quantitative analysis of marble waste using WDX-ray fluorescence Spectrometer Model: S4 Pioneer from braker-axs Germany.

\begin{tabular}{cc}
\hline Component & $\mathrm{Wt} \%$ \\
\hline $\mathrm{CaO}$ & 68.6 \\
$\mathrm{MgO}$ & 22.13 \\
$\mathrm{SiO}_{2}$ & 3.89 \\
$\mathrm{Al}_{2} \mathrm{O}_{3}$ & 2.785 \\
$\mathrm{Fe}_{2} \mathrm{O}_{3}$ & 0.603 \\
$\mathrm{Cr}_{2} \mathrm{O}_{3}$ & 0.24 \\
$\mathrm{ZnO}$ & 0.20 \\
$\mathrm{TiO}$ & 0.549 \\
\hline
\end{tabular}


The above observations indicate that the marble powder is basically composed of calcium carbonate, magnesium carbonate with small amount of silicate, aluminum oxide and iron oxide.

\subsection{Rheological Characteristics}

The physical properties of rubber blends are also responsible for the quality of rubber products for any use. Therefore, it is necessary to study the rheological behavior of the uncured rubber blends. Table 1 summarized the rheological characteristics of EPDM/CR blends containing marble powder. The obtained data shows that the increase in $\mathrm{CR}$ content in blends resulted in increasing the minimum torque and maximum torque till the blend ratio reached $85 / 15$ after that the slight decrease in minimum torque and maximum torque has observed. It can be seen that the minimum torque which reflect the minimum viscosity of the blends is affected by the increasing amount of $\mathrm{CR}$ in the blend composition. The maximum torque has the same behavior as to the minimum torque. In addition the optimum cures time and scorch time increased with the increasing of $\mathrm{CR}$ ratio in the blend composition. It is obvious that maximum torque which reflects the cross-linking behavior of the blends increasing CR up till in ratio 85/15 after which it decreases. The scorch time of MS filled EPDM/CR blends increases with increasing the CR content in the blends and give improved scorch safety with the addition of the CR. The optimum cure time first decreased and then increased with increasing CR content in the blends. The reason for such increase in optimum cure time may be due to the presence of $\mathrm{CR}$ content in blends, which increases the relative site which require more time for cross linking in rubber blends.

The calculated values of CRI are also given in this table. The value shows that the CRI increases with the increasing CR content in EPDM/CR blend composition. This indicates that the $\mathrm{CR}$ as a polar in nature is a cure activating compound in various EPDM/CR blends. The increasing of CR amount increases the activating sites for vulcanization.

\subsection{Mechanical Properties}

The studies of mechanical properties in rubber blends are very important characterization. Variations in tensile strength, elongation at break and tear strength with increasing the amount of CR in EPDM/CR blends are provided in Figures 1-3 respectively. It can be seen that the lower content of CR in EPDM/CR blends had lower values of tensile strength as compared to higher amount of $\mathrm{CR}$ present in blends low values for the tensile strength result $\mathrm{CR}$ act as a coupling agent in the blends. The tensile strength increased with increasing amount of $\mathrm{CR}$ in said

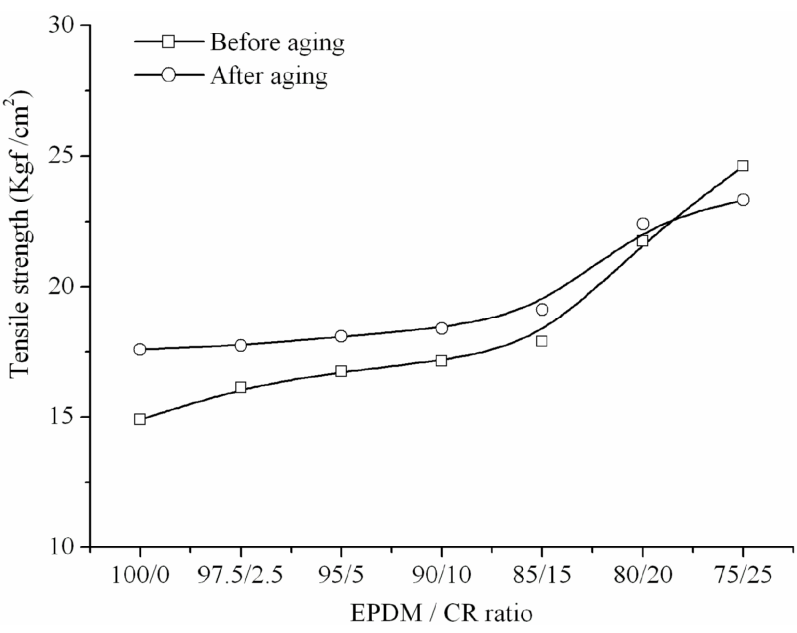

Figure 1. Tensile strength of MS filled EPDM/CR blends.



Figure 2. Elongation at break of MS filled EPDM/CR blends.



Figure 3. Tear strength of MS filled EPDM/CR blends.

blends. The presence of polarity of CR is believed to play a significant role in raising a good interaction and compatibility with EPDM in marble powder filled EPDM/CR 
blends. The tear strength also follows the same trends as that of tensile strength. Elongation at break showed their values gradually decrease with increasing CR content in the blends. The decrease in the values of elongation at break with increasing CR ratio in the blends is the resulting of higher cross linking.

The values of hardness of the marble powder filled EPDM/CR blends shown in Figure 4 that no considerable variation in hardness occurs. The hardness values slightly increased due to the better interaction of CR in EPDM rubber.

The abrasion loss test results for MS filled EPDM/CR shown in Figure 5. It is clear that the abrasion resistance of blends gradually decreases with increasing CR ratio in the blends. The rebound resilience test results for MS filled EPDM/CR shown in Figure 6. The rebound resilience values also follow the same pattern. The low values of abrasion and rebound resilience indicates improvement in the CR with EPDM in particular blends.

Compression set is a measure of the ability of rubber vulcanizes to retain their elastic properties after prolonged compression at constant strain under a specific set of condition and its permanent set of rubber vulcanizes. The poor performance of rubber compounds in terms of compression set is attributed to uncross-linked chains, which do not contribute to the permanent network and are able to relax during the compression stage. The result of compression set is also present in Figure 7. The results of MS filled EPDM/CR blends show no significant variation in their results. It is due to the effective network chain or crosslink in the deformed state. The lower values of blends indicate the best material for the compression state.

\subsection{Thermal Oxidative Aging}

Figures 1-7 show the effect of thermal oxidative aging on the physical and mechanical properties after aging and

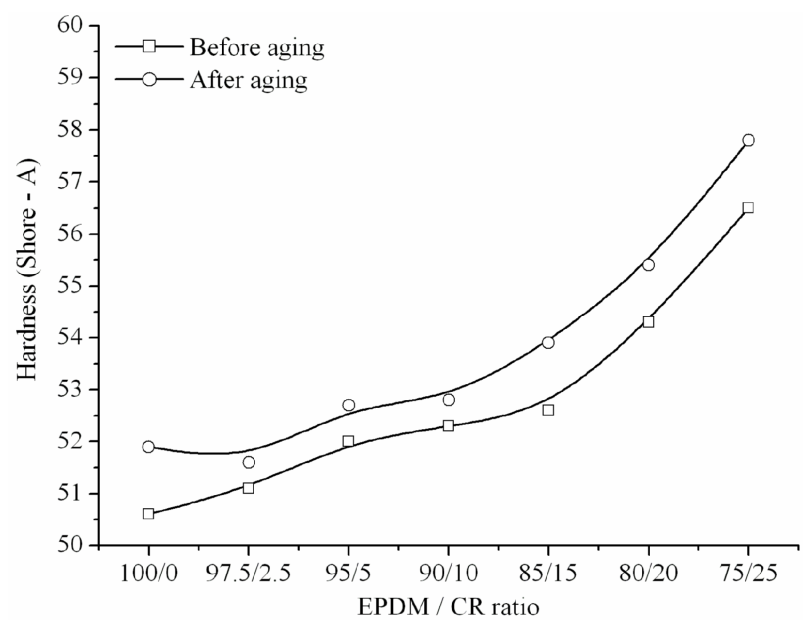

Figure 4. Hardness of MS filled EPDM/CR blends.

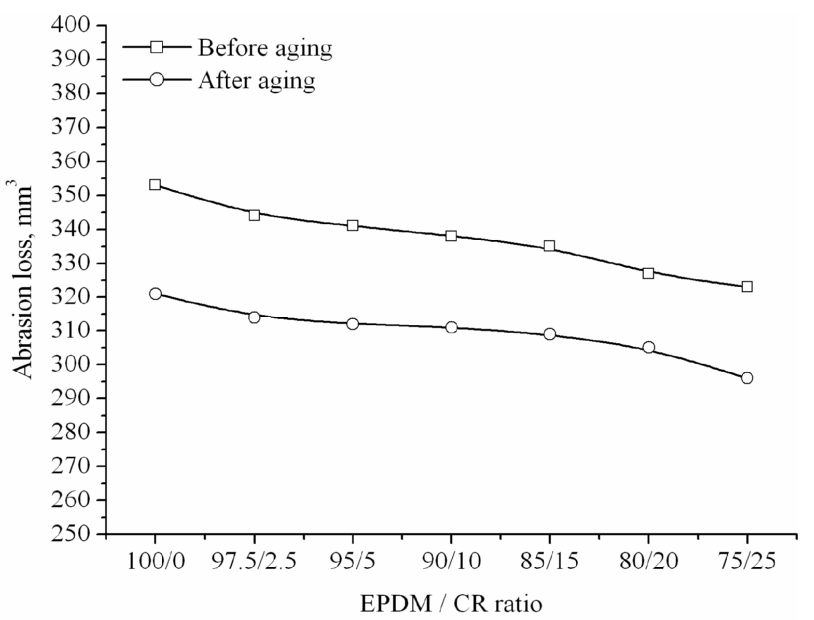

Figure 5. Abrasion loss of MS filled EPDM/CR blends.

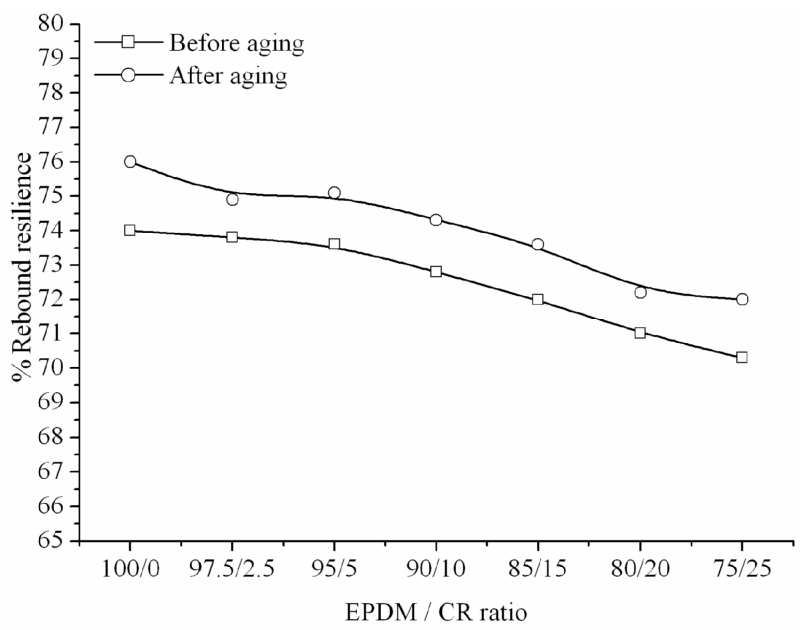

Figure 6. Rebound resilience of MS filled EPDM/CR blends.

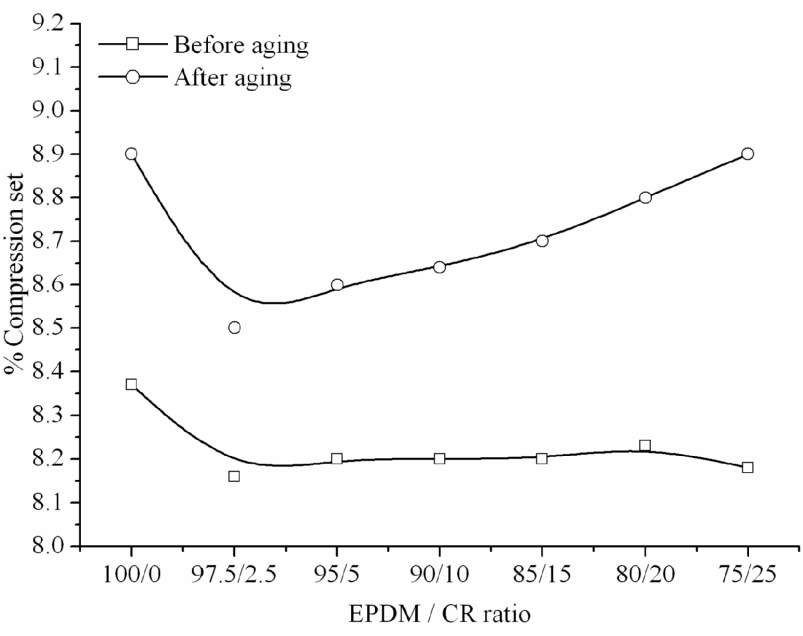

Figure 7. Compression set of MS filled EPDM/CR blends.

percentage of retention. The effect of blend ratio of MS filled EPDM/CR blends as aging resistance which represented in terms of relative value at $100^{\circ} \mathrm{C}$ for 96 hours. 
The results show that regarding the blend ratio aging at $100^{\circ} \mathrm{C}$ leads to increasing the tensile strength till EPDM/CR blends $80 / 20$ and then further increasing the CR ratio in blend leads to reduction in tensile strength. It is due to the CR dilution in blend and double bond in CR which loss reactivity to thermal oxidative degradation. The elongation at break of MS filled EPDM/CR blends tend to decrease with increasing CR ratio in blends. It is due to the post curing effect. This effect is also seen in abrasion losses and rebound resilience properties of blends. Similar effects of post curing also found in hardness of the MS filled EPDM/CR blends. Table 3 shows the Percentage of retention of Tensile Strength, Elongation at break, Tear Strength, Hardness, Abrasion Loss, Rebound Resilience and Compression Set of MS with different EPDM/CR ratio. The retention in tensile strength of the blends decreased with increase in CR content in blends. The retention in elongation at break increased with increasing $\mathrm{CR}$ ratio in blends. This may be possible due to disturbance the elasticity of rubber chain after aging, providing more stiffness to the blends.

\subsection{Swelling Parameters}

The swelling measurement has been carried out for MS filled EPDM/CR blends crosslinked at different blend ratio. Toluene, n-hexane and carbon tetrachloride solvents were used. The choice of these three solvent was based on the fact that all the three solvents different from each other. Toluene is aromatic. n-hexane is an aliphatic while carbon tetrachloride is chlorinated solvent.

These solvents have different ability to dissolve or to swell the cured rubber blends. The swelling results in Table 4 show that the vulcanizates have more affinities for toluene and n-hexane as compared to carbon tetrachloride. The compound contains only EPDM swell most in all the solvents with the trend reducing as the concentration

Table 3. Percentage of retention for the tensile strength, elongation at break, tear strength, hardness, abrasion loss, rebound resilience and compression set of MS with different EPDM/CR ratio.

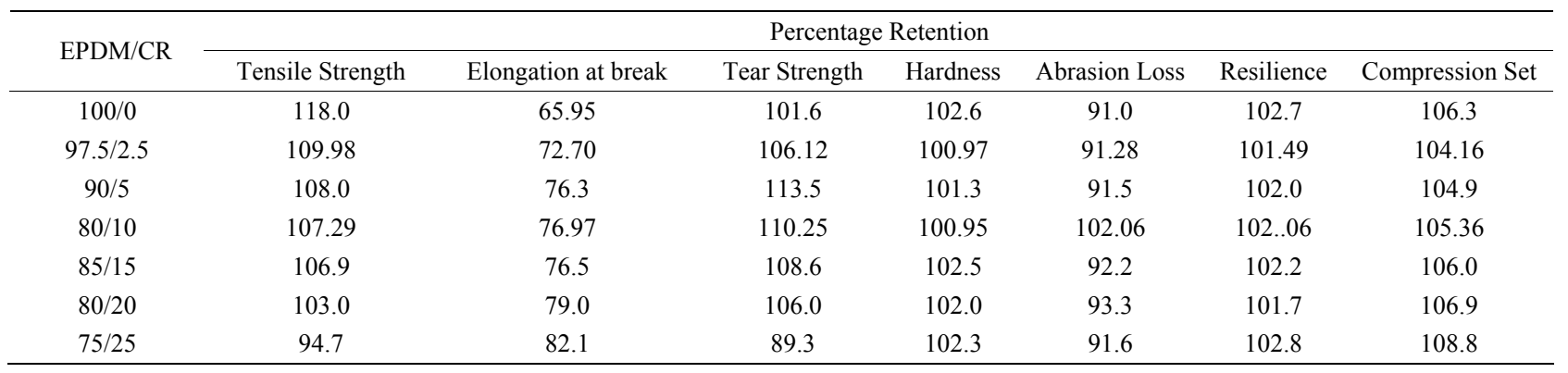

Table 4. Swelling parameters of MS filled EPDM/CR blends.

\begin{tabular}{|c|c|c|c|c|c|c|c|c|c|c|}
\hline \multirow[b]{2}{*}{ Solvent } & \multirow[b]{2}{*}{ EPDM/CR } & \multicolumn{3}{|c|}{ Mol \% Up Take $\left(Q_{t}\right)$} & \multicolumn{3}{|c|}{ Swelling Index (SI) } & \multicolumn{3}{|c|}{ Percentage Solubility } \\
\hline & & $\begin{array}{l}\text { Before } \\
\text { Aging }\end{array}$ & $\begin{array}{l}\text { After } \\
\text { Aging }\end{array}$ & $\%$ Retention & $\begin{array}{l}\text { Before } \\
\text { Aging }\end{array}$ & $\begin{array}{l}\text { After } \\
\text { Aging }\end{array}$ & $\%$ Retention & $\begin{array}{l}\text { Before } \\
\text { Aging }\end{array}$ & $\begin{array}{l}\text { After } \\
\text { Aging }\end{array}$ & $\%$ Retention \\
\hline \multirow{7}{*}{ Toluene } & $100 / 0$ & 1.43 & 1.41 & 98.6 & 1.32 & 1.30 & 98.48 & 6.50 & 5.85 & 90.00 \\
\hline & $97.5 / 2.5$ & 1.40 & 1.38 & 98.57 & 1.32 & 1.30 & 98.48 & 6.21 & 5.58 & 89.85 \\
\hline & $95 / 05$ & 1.41 & 1.33 & 94.32 & 1.30 & 1.23 & 94.61 & 5,63 & 4.41 & 78.15 \\
\hline & $90 / 10$ & 1.36 & 1.28 & 94.11 & 1.23 & 1.15 & 93.5 & 5.22 & 4.09 & 78.36 \\
\hline & $85 / 15$ & 1.24 & 1.21 & 97.58 & 1.14 & 1.11 & 97.36 & 4.20 & 3.70 & 88.09 \\
\hline & $80 / 20$ & 1.05 & 0.98 & 93.33 & 0.97 & 0.90 & 92.78 & 3.90 & 3.4 & 87.17 \\
\hline & $75 / 25$ & 1.02 & 0.96 & 94.11 & 0.93 & 0.88 & 95.16 & 3.06 & 3.04 & 99.35 \\
\hline \multirow{6}{*}{ n-Hexane } & $100 / 00$ & 1.055 & 1.000 & 94.78 & 0.908 & 0.860 & 94.71 & 4.40 & 4.28 & 97.27 \\
\hline & $97.5 / 2.5$ & 1.043 & 0.987 & 94.63 & 0.900 & 0.852 & 94.66 & 4.34 & 4.23 & 97.46 \\
\hline & $95 / 05$ & 1.039 & 0.985 & 94.77 & 0.893 & 0.845 & 94.62 & 4.27 & 4.18 & 97.89 \\
\hline & $90 / 10$ & 1.00 & 0.958 & 95.8 & 0.881 & 0.835 & 94.77 & 4.07 & 3.94 & 96.8 \\
\hline & $85 / 15$ & 0.996 & 0.966 & 96.98 & 0.856 & 0.831 & 97.08 & 3.57 & 3.40 & 95.23 \\
\hline & $75 / 25$ & 0.888 & 0.840 & 94.59 & 0.764 & 0.723 & 94.63 & 3.16 & 2.88 & 91.13 \\
\hline \multirow{7}{*}{$\begin{array}{l}\text { Carbon } \\
\text { tetrachloride }\end{array}$} & $100 / 0$ & 0.828 & 0.735 & 88.77 & 1.276 & 1.132 & 88.71 & 6.67 & 6.02 & 90.25 \\
\hline & $97.5 / 2.5$ & 0.828 & 0.744 & 89.85 & 1.272 & 1.13 & 88.83 & 6.46 & 5.8 & 89.78 \\
\hline & $95 / 05$ & 0.825 & 0.719 & 87.15 & 1.270 & 1.108 & 87.24 & 6.35 & 5.64 & 88.81 \\
\hline & $90 / 10$ & 0.818 & 0.710 & 86.78 & 1.255 & 1.09 & 86.85 & 6.17 & 5.35 & 86.71 \\
\hline & $85 / 15$ & 0.807 & 0.695 & 86.12 & 1.243 & 1.071 & 86.16 & 6.10 & 5.18 & 84.92 \\
\hline & $80 / 20$ & 0.752 & 0.643 & 85.50 & 1.158 & 0.990 & 85.49 & 5.74 & 4.91 & 85.54 \\
\hline & $75 / 25$ & 0.687 & 0.633 & 92.14 & 1.056 & 0.975 & 92.15 & 3.90 & 3.66 & 93.84 \\
\hline
\end{tabular}


of $\mathrm{CR}$ ratio increases, with the increasing of the $\mathrm{CR}$ amount in the blends. The mole percentage uptake, swelling index and solubility of cured rubber in solvent is decreased. The lowest mole percentage uptake and swelling index was reduced with the compound contain EPDM/CR $75 / 25$ blend ratio. It means that the ratio of $\mathrm{CR}$ in $\mathrm{MS}$ filled EPDM/CR blends increases the crosslinked density, causing limitations in penetration of solvents into the cured blends. It is also means that higher amount of CR in cured blends resistance to penetrate the solvent into the cured rubber blends.

It is also observed that the uptake of aromatic solvent (toluene) is higher than aliphatic (n-hexane). Maximum uptake was found with toluene followed by n-hexane and carbon tetrachloride. In carbon tetrachloride, it was lower in all the swelling results. It may be due to the higher molecular weight of carbon tetrachloride as compared to toluene and n-hexane.

The soluble fraction in different solvent also indicates that the pure EPDM vulcanizate have maximum soluble fraction. However the soluble fraction of other cured blends decreased with increasing of $\mathrm{CR}$ ratio in the blends.

The decrease in all swelling tests after aging for 96 hours at $100^{\circ} \mathrm{C}$ is expected to be related to the formulation of excessive crosslinked structure which may due to the post curing effect.

\section{Conclusions}

From the results obtained. It can be concluded.

The cure characteristics, mechanical and swelling properties of MS filled EPDM/CR blends mainly depend on the blend ratio.

MS filled EPDM/CR blends tend to reduce of elongation at break, resilience, abrasion loss, mol \% uptake, swelling index and percentage of soluble fraction, but scorch time, optimum cure time, cure rate index, tensile strength, tear strength and hardness values shows the opposite trend with increasing the CR content in MS filled EPDM/CR blends. While minimum torque and maximum torque of the blend first increases and then decrease. The blend ratio not much influenced on compression set properties. Accelerated aging behavior of MS filled EPDM/CR blends also affected with changed the blend ratio.

This study show that marble sludge powder can be used as a cheaper filler in EPDM/CR blends for the low cost of the final product in non-critical application area like door mats, car mats, widow channels, tubing etc.

\section{REFERENCES}

[1] Halimatuddahliana and H. Ismail, "Properties of Polypropylene (PP)/Ethylene-Propylene Diene Terpolymer
(EPDM)/ Natural Rubber (NR) Vulcanized Blends: The Effect of N, N-m-Phenylenebismaleimide (HVA-2) Addition," Polymer-Plastics Technology and Engineering, Vol. 48, No. 1, 2008, pp. 25-33. doi:10.1080/03602550802539155

[2] X. D. Mao, S. A. Xu and C. F. Wu, "Dynamic Mechanical Properties of EPDM Rubber Blends," Polymer-Plastics Technology and Engineering, Vol. 47, No. 2, 2008, pp. 209-214. doi:10.1080/03602550701817611

[3] J. Anuar, M. Mariatti and H. Ismail, "Study on Tensile, Electrical, and Thermal Properties of Aluminum Particle Filled Natural Rubber (NR) and Ethylene-Propylene-Diene (EPDM) Composites," Polymer-Plastics Technology and Engineering, Vol. 46, No. 12, 2007, pp. 1201-1206. doi:10.1080/03602550701575920

[4] J. T. Sunil and J. Rani, "EPDM/CIIR Blends: Effect of EPDM Grade on Mechanical Properties," International Journal of Polymeric Materials, Vol. 56, No. 7, 2007, pp. 743-758. doi:10.1080/00914030601100771

[5] M. A. M. Eid and D. E. El-Nashar, "Filling Effect of Silica on Electrical and Mechanical Properties of EPDM/NBR Blends," Polymer-Plastics Technology and Engineering, Vol. 45, No. 6, 2006, pp. 675-684. doi:10.1080/03602550600609325

[6] N. Suma, J. Rani and K. E. George, "Investigation of the Processability of NR/IIR and NR/EPDM Blends Using a Torque RheometerInter," International Journal of Polymeric Materials, Vol. 20, No. 3-4, 1993, pp. 145-158. doi:10.1080/00914039308048357

[7] S. H. Botros and M. L. Tawfic, "Preparation and Characteristics of EPDM/NBR Rubber Blends with BIIR as Compatibilizer," Polymer-Plastics Technology and Engineering, Vol. 44, No. 2, 2005, pp. 209-227. doi:10.1081/PTE-200048518

[8] T. Münir and T. Mura, "Dynamically Vulcanized EPDM/ PP (40/60) Blends," International Journal of Polymeric Materials, Vol. 55, No. 12, 2006, pp. 1065-1073. doi:10.1080/00986440600643023

[9] I. Rezaein, P. Zahedi and M. S. Loghmani, "Formulation and Curing Characterization of EPDM/NR and EPDM/ SBR Polyblends Used in Metallic Surfaces Rubber Lining," Journal of Applied Polymer Science, Vol. 113, No. 2, 2006, pp. 849-854. doi:10.1002/app.29910

[10] T. Zaharescu, S. Jipa and M. Giurginca, "Radiochemical Processing of EPDM/NR Blends," Journal of Macromolecular Science, Part A: Pure and Applied Chemistry, Vol. 35, No. 7, 1998, pp. 1093-1102. doi:10.1080/10601329808002103

[11] K. Sahakaro, C. Pongpaiboom and C. Nakason, "Improved Mechanical Properties of NR/EPDM Blends by Controlling the Migration of Curative and Filler via Reactive Processing Technique," Journal of Applied Polymer Science, Vol. 111, No. 4, 2009, pp. 2035-2043. doi:10.1002/app.29193

[12] T. K. Bhaumik, B. R. Gupta and A. K. Bhowmick, "Tack and Green Strength of Blends of Bromobutyl and EPDM Rubbers. I. Unfilled Gum Blends," The Journal of Adhesion, Vol. 24, No. 2-4, 1987, pp. 183-198. doi: $10.1080 / 00218468708075426$

[13] P. Soe-Oui, C. Sirisinaha and H. Hatthapanit, "Effect of Blends Ratio on Aging, Oil and Ozone Resistance of Sil- 
ica-Filled Chloroprene Rubber/Natural Rubber (CR/NR) Blends," Express Polymer Letters, Vol. 1, No. 1, 2007, pp. 8-12. doi:10.3144/expresspolymlett.2007.3

[14] F. L. Chen, L. Cen and C. H. Lei, "Study on the Milling Behavior of Chloroprene Rubber Blends with Ethylene-Propylene-Diene Monomer Rubber, Polybutadiene Rubber, and Natural Rubber," Polymer Composites, Vol. 28, No. 5, 2007, pp. 667-673.

[15] A. F. Younan, S. L. Abd-El-Messleh and A. A. Gasser, "Electrical and Mechanical Properties of Ethylene Propylene Diene Monomer-Chloroprene Rubber Blend Loaded with White and Black Fillers," Journal of Applied Polymer Science, Vol. 70, No. 10, 1998, pp. 2061-2068. doi:10.1002/(SICI)1097-4628(19981205)70:10<2061::AI D-APP22>3.0.CO;2-F

[16] A. Das, S. C. Debnath, D. De and D. K. Basu, "Evalution of Physical Properties and Curing Characteristics of Silica Filled EPDM in Presence of Chloroprene Rubber," Journal of Applied Polymer Science, Vol. 93, No. 1, 2004, pp. 196-200. doi:10.1002/app.20452

[17] S. J. Issam and J. M. Ibrahim, "Testing and Evaluation of Rubber-Base Composites Reinforced with Silica sand," Journal of Composite Materials, Vol. 40, No. 23, 2006, pp. 2099-2112.
[18] H. Ismail and R. Ramli, "Organoclay Filled Natural Rubber Nanocomposites: The Effect of Filler Loading and Mixing Method," Journal of Reinforced Plastics and Composites, Vol. 27, No. 16-17, 2008, pp. 1909-1924. doi: $10.1177 / 0731684407082541$

[19] J. Zhang, Q. J. Ding, B. X. Hu, B. L. Liu, and J. Shen, "Preparation and Characterization of Composites: Ethylene-Propylene-Diene Terpolymer-Graft-Maleic Anhydride/ $\mathrm{CaCO}_{3}$," Journal of Applied Polymer Science, Vol. 101, No. 3. 2006, pp. 1810-1815. doi:10.1002/app.23582

[20] H. Binici, K. Hasan and Y. Salih, "Influence of Marble and Limestone Dusts as Additives on Some Mechanical Properties of Concrete," Scientific Research and Essay, Vol. 2, No. 9, 2007, pp. 372-379.

[21] M. Karasahim and S. Terzi, "Evaluation of Marble Waste Dust in the Mixture of Asphaltic Concrete," Constrution and Building Materials, Vol. 21, No. 3, 2007, pp. 616620 .

[22] S. Agrawal, S. Mandot, S. Bandyopadhyay, R. Mukhopadhyay, M. Dasgupta, P. P. De and A. S. Deuri, "Use of Marble Waste in Rubber Industry: Part I (In NR Compound)," Progress in Rubber, Plastics and Recycling Technology, Vol. 20, No. 3, 2004, pp. 229-246. 